\title{
Tantangan Kaum Freelancer Dan Pemerintah Indonesia Di Era Perkembangan Teknologi Digital (Analisis Kritik Globalisasi)
}

\author{
Ahmad Hidayah ${ }^{1}$ \\ Universitas Gadjah Mada
}

\begin{abstract}
This article discusses the challenges for you as a freelancer and the Indonesian government in the era of digital technology developments. This article uses a qualitative research method (discourse analysis approach) using online data collection techniques. This article describes how the development of freelancers in Indonesia, this phenomenon is a form of current technological developments. Based on this, there are things that need to be re-criticized regarding the development of freelancers. We need to pay attention to the uncertainty regarding social security and other threats they may encounter. Based on this, this article tries to provide a critical view of the Indonesian Government regarding its role and responsibilities regarding social security issues that are not yet available to freelancers in Indonesia because it is stipulated in the 1945 Constitution.
\end{abstract}

Keywords: Freelancer, Uncertainty, Threats, Social Security, Digital Technology

\begin{abstract}
Abstrak
Artikel ini membahas mengenai tantangan kau freelancer dan Pemerintah Indonesia di era perkembangan teknologi digital. Artikel ini menggunakan metode penelitian kualitatif (pendekatan analisis wacana) dengan menggunakan teknik pengumpulan data secara online. Artikel ini mendeskripsikan bagaimana perkembangan kaum freelancer di Indonesia, fenomena tersebut merupakan bentuk dari perkembangan teknologi saat ini. Berdasarkan hal tersebut ada hal yang perlu dikritisi ulang mengenai perkembangan freelancer tersebut. Kita perlu memerhatikan ketidakpastian mengenai jaminan sosial dan ancaman-ancaman lain yang kemungkinan mereka temui. Berdasarkan hal tersebut artikel ini mencoba memberikan pandangan kritis terhadap Pemerintah Indonesia mengenai peran dan tanggungjawabnya mengenai permasalahan jaminan sosial yang belum tersedia bagi para freelancer di Indonesia karena hal tersebut telah tertuang di dalam UUD 1945.
\end{abstract}

Kata Kunci: Freelancer, Ketidakpastian, Ancaman, Jaminan Sosial, Teknologi Digital

\footnotetext{
1 ahmad.hidayah101295@gmail.com
} 


\section{Pendahuluan}

Globalisasi bukanlah suatu istilah yang asing bagi manusia yang hidup pada zaman era digital ini. Kepastian dan kejelasan mengenai pengertian tunggal dari globalisasi sampai dengan saat ini masih menjadi perdebatan ilmiah karena sulitnya mendefinisikan secara konkret. Penyebab hal tersebut para intelektual masih menjadikan wacana globalisasi sebagai ladang diskusi karena kompleksitas dan multi interpretasi dari globalisasi, apakah dimaknai sebagai fenomena sosial, apakah dimaknai sebagai perkembangan teknologi atau dapat dimaknai sebagai wujud perkembangan kapitalisme dunia (Jati, 2013), namun dalam hal ini penulis lebih menyetujui bahwa sebenarnya globalisasi dan perkembangan teknologi pada dewasa ini merupakan wujud perkembangan terbaru kapitalisme dunia.

Berangkat dari penjelasan di atas, maka artikel ini mencoba mengerucutkan lagi dari globalisasi tersebut, salah satu efek dari globalisasi adalah mampu menyebabkan percepatan perkembangan teknologi. Sama halnya dengan globalisasi, begitu cepat dan pesatnya perubahan dan inovasi teknologi digital dewasa ini menyebabkan perdebatan antara kubu optimis dan pesimis dalam menghadapi perkembangan teknologi digital dewasa ini. Kaum optimis menyatakan bahwa teknologi digital secara sukses mentransformasikan dunia, menawarkan bentuk-bentuk komunitas yang baru, alternatif atau cara-cara baru dalam upaya mengetahui suatu hal dan merasakan, semakin banyaknya proses inovasi kreatif, kultur partisipatif, aktivisme dalam bentuk baru dan persemaian demokrasi (Chandler \& Fuchs, 2019). Berbanding terbalik dengan kaum optimis tersebut, kaum pesimis beranggapan bahwa kemajuan teknologi digital tidak mempunyai dampak positif sama sekali. Kemajuan teknologi digital hanya memerparah dan memerdalam serta memerluas dominasi (hegemoni) dalam bentuk-bentuk yang baru seperti jejaring otoritarianisme, dehumanisasi digital, alinenasi seperti yang terjadi pada revolusi 2.0, penguatan eksploitasi dan bangkitnya surveillance society (Chandler \& Fuchs, 2019).

Berangkat dari penjelasan dari Fuchs (2019) mengenai sudut pandang optimis terhadap kemajuan teknologi maka inovasi-inovasi yang terjadi di era terbaru ini juga mengubah tren manusia dalam bekerja dan mencari pekerjaan. Dahulu, apabila individu tidak bekerja di dalam sebuah instansi formal maka hidup orang tersebut dianggap tidak jelas arahnya akan ke mana, tidak jelas masa depannya dan masih banyak stereotip masyarakat Indonesia mengenai orang-orang yang memilih bekerja tidak pada institusi formal. Berbeda dengan kondisi yang 
penulis amati pada dewasa ini stereotip tersebut telah berubah secara signifikan sehingga masyarakat Indonesia dewasa ini tidak terlalu terpaku untuk bekerja dan mencari kerja di sektor formal.

Melihat realitas yang terjadi dewasa ini, globalisasi dan kemajuan teknologi digital mampu mengubah paradigma masyarakat Indonesia terhadap pilihan rasional untuk memilih pekerjaan apa yang akan digunakan sebagai cara untuk bertahan hidup. Semenjak masuknya era perubahan (teknologi digital) ini mampu membuat orang-orang semakin mudah karena semakin beragamnya jenis pekerjaan yang dapat diakses, namun di lain sisi mampu juga menimbulkan perasaan cemas atau merasa terancam (Mustofa, 2018). Ketidakpastian nasib para freelancer di Indonesia dalam hal jaminan sosialnya juga merupakan salah satu efek serta kritik dari adanya globalisasi. Dengan adanya kemajuan dari globalisasi ini masyarakat seolaholah dipermudah olehnya, padahal dibalik segala kemudahan tersebut ada hal yang luput dari globalisasi dan terutama oleh Pemerintah Indonesia.

Berangkat dari pemaparan di atas, pada artikel ini penulis menganalisis dan membahas mengenai Indonesia yang ikut masuk ke dalam arus globalisasi (teknologi digital) saat ini menyebabkan semakin meningkatnya tren pekerjaan freelancer di Indonesia. Menurut hemat penulis, kondisi tersebut tidak dapat diterima begitu saja tanpa memikirkan bagaimana efeknya ke depan? Apakah jenis pekerjaan tersebut akan bisa bertahan selamanya atau hanya sebuah tren musiman saja? Lantas apabila jenis pekerjaan freelancer dapat dijadikan sumber penghasilan bagaimana dengan jaminan sosial mereka sebagai freelancer? Nampaknya hal tersebut sampai dengan saat ini belum menjadi titik fokus kebijakan pemerintahan Indonesia.

\section{Metode Penelitian}

Artikel ini menggunakan metode kualitatif. Dalam proses penulisan, penulis menggunakan pendekatan fenomenologi. Pendekatan tersebut digunakan agar artikel ini dapat membongkar pemahaman tentang realitas sosial, peristiwa, dan proses interaksi. Dalam hal ini maksud dan tujuan penggunaan metode penelitian tersebut agar penulis dapat mengungkap fenomena yang relevan terjadi pada dewasa ini yaitu tantangan kaum freelancer di Indonesia. Berdasarkan hal tersebut, pada dasarnya artikel ini adalah bentuk dari investigasi untuk memahami fenomena sosial peralihan pekerjaan di era globalisasi di mana jenis pekerjaan memiliki tantangan dan risiko tersendiri. Artikel ini menggunakan data melalui wawancara dan 
pengumpunan data sekunder secara online. Pengumpulan data ini mampu memberikan alternatif bagi peneliti dalam pengumpulan data kualitatif dan untu keabsahan data maka peneliti melakukan proses triangulasi data.

\section{Hasil dan Pembahasan}

\section{Perkembangan Freelancer di Indonesia sebagai Salah Bentuk Kemajuan di era}

\section{Globalisasi (Teknologi Digital)}

Efek yang paling dapat kita rasakan dari globalisasi adalah kemampuannya untuk menyebabkan percepatan perkembangan teknologi. Berangkat dari penjelasan dari Fuchs (2019) bahwa kemajuan teknologi yang terjadi di era terbaru ini ternyata juga mengubah tren manusia dalam bekerja. Dahulu, apabila individu tidak bekerja di dalam sebuah instansi formal maka hidup orang tersebut dianggap tidak jelas arahnya akan ke mana, tidak jelas masa depannya dan masih banyak stereotip masyarakat Indonesia mengenai orang-orang yang memilih bekerja tidak pada institusi formal. Hal yang menjadi sorotan utama dalam artikel ini adalah mengenai pekerja sektor informal yang bekerja sebagai freelancer.

Pernyataan di atas didukung dengan hasil survei Badan Pusat Statistik (BPS) pada bulan Agustus 2018 data menunjukkan sebanyak 56,8 \% masyarakat Indonesia yang bekerja di sektor informal (wirausaha dan termasuk pekerja lepas atau freelancer). Selanjutnya, data dari BPS pada bulan Mei tahun 2019 menunjukkan bahwa angkatan kerja Indonesia (usia 15 s.d 64 tahun) ada sebanyak 136,18 juta orang. Jumlah angkatan kerja sebanyak 136,18 juta orang tersebut terbagi lagi menjadi 129,36 juta orang yang memiliki pekerjaan atau bekerja di sektor formal sedangkan mereka yang termasuk ke dalam kategori bekerja di sektor informal berjumlah 6.82 juta orang (Kharisma, 2019). Data selanjutnya menguti dari Majalah Tempo (Tarigan, 2019) memrediksi bahwa jumlah freelancer di Indonesia ini ada sekitar 4,55 \% atau sekitar 5,89 juta orang dari jumlah pekerja sektori informal dari BPS. Berdasarkan data tersebut, maka dapat disimpulkan bahwa bekerja sebagai freelancer mulai di lirik oleh masyarakat Indonesia. Pernyataan tersebut didukung oleh hasil survei yang dilakukan Sribulancer menyatakan bahwa angka freelancer di Indonesia mengalami peningkatan sebanyak $16 \%$ pada tahun 2019 jika dibandingkan pada tahun 2018 lalu. 
Tantangan Kaum Freelancer Dan Pemerintah Indonesia Di Era Perkembangan Teknologi Digital (Analisis Kritik Globalisasi)

Dewasa ini kaum freelancer sangat dibutuhkan keberadaannya (Grabher, 2001, 2002) dalam dunia kerja di era globalisasi dan kemajuan teknologi digital saat ini. Meskipun ada beberapa anggapan bahwa kedudukan seorang freelancer hanya sebagai "eksternal collaborators" yang juga bisa berafiliasi terhadap beberapa perusahaan yang lain (Watson \& Beaverstock, 2016). Anggapan tersebut nampaknya sesuai dengan kondisi Indonesia saat ini. Situs Sribulancer melakukan survei mengenai hasil pertumbuhan freelancer di Indonesia, berikut data statistik hasil surveinya

Gambar 1.

Jumlah Influencer dan Client Influencer di Indonesia

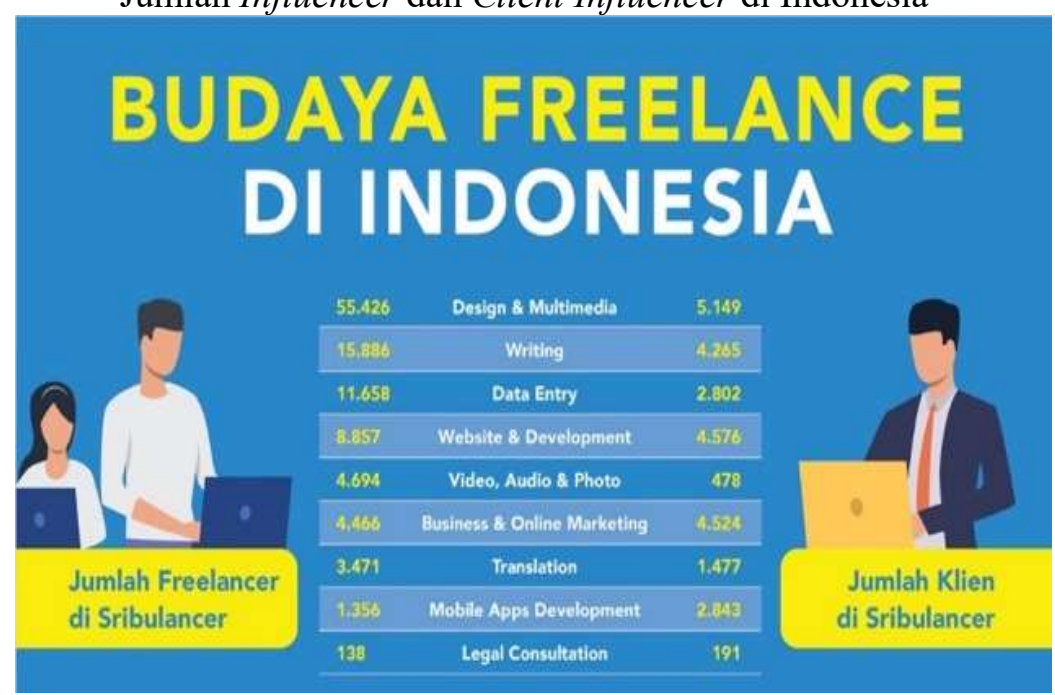

Sumber: www.sribulencer.com

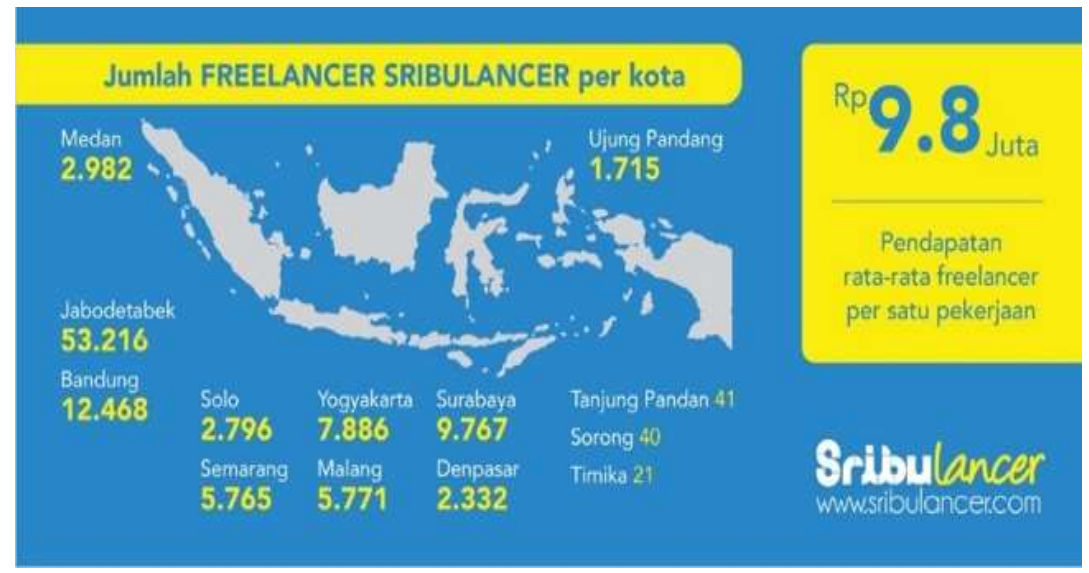

Gambar 2. Sebaran Influencer pada Beberapa Kota di Indonesia Sumber: www.sribulencer.com 
Berdasarkan gambar 1 dan gambar 2 di atas dapat dilihat bahwa pada era kemajuan teknologi dewasa ini membuat masyarakat Indonesia mulai tidak berorientasi lagi pada pekerjaan di sektor formal dikarenakan adanya pergeseran cara pandang masyarakat Indonesia dalam menghadapi era perkembangan teknologi digital yang terjadi pada dewasa ini. Realitas tersebut sejalan dengan pendapat dari Hardt dan Negri (2004) serta Lazzarato (2000) dalam (Juliawan, 2018) bahwa salah satu dampak dari kemajuan teknologi digital ini adalah perubahan formasi tenaga kerja dimana dahulu masyarakat Indonesia hanya tertarik dan dituntut untuk bekerja di sektor formal namun saat ini lebih flexible memilih pekerjaan sebagai freelancer. Hal tersebut dapat dikatakan sebagai akumulasi immaterial labour yang kenyataannya tidak terlihat dan susah untuk didefinisikan namun memunyai nilai tukar yang tinggi. Alasan lain mengapa pekerja freelancer semakin berkembang di Indonesia disebabkan karena pesatnya perkembangan internet yang terjadi pada era teknologi digital saat ini sehingga memudahkan para freelancer serta bagi mereka yang membutuhkan tenaga freelancer untuk bertemu dan bertransaksi (cross border transaction). Internet digunakan bagi pekeja freelancer dan client untuk bertemu dan bertransaksi guna mengatasi kendala waktu dan geografi antar kedua pihak tersebut (Widodo, 2019). Alasan terakhir mengapa freelancer di Indonesia semakin berkembang disebabkan karena mereka yang bekerja sebagai freelancer memiliki kebebasan dalam waktu kerja karena sistem kerja mereka tidak terikat waktu seperti para pekerja formal (Shevchuk et al., 2019).

\section{Ketidakpastian Jaminan Sosial bagi Freelancer Indonesia di Era Globalisasi (Teknologi Digital) sebagai Salah Satu Ancaman Freelancer}

Di era globalisasi dewasa ini mampu mengubah segalanya. Salah satu contohnya nyata yang terjadi di Indonesia adalah kemampuannya mengubah paradigma masyarakat Indonesia terhadap pilihan rasional untuk memilih pekerjaan apa yang akan digunakan sebagai cara untuk bertahan hidup. Bagi kaum optimis, hal tersebut merupakan kemajuan, akan tetapi ada hal yang luput dari pandangan kita mengenai kemajuan tersebut. Menurut hemat penulis, ada yang perlu diperhatikan oleh masyarakat dan Pemerintahan Indonesia mengenai fenomena perkembangan freelancer di Indonesia saat ini, yaitu bagaimana dengan jaminan sosial bagi mereka yang memutuskan untuk bekerja sebagai freelancer? Hal ini sangat penting untuk diperhatikan, 
mengingat bahwa salah satu keunggulan dari pekerja di sektor formal adalah mereka mendapatkan akses jaminan sosial yang telah disediakan oleh tempat mereka bekerja. Berbeda dengan mereka yang bekerja sebagai freelancer harus memiliki kesadaran mereka sendiri terhadap jaminan sosial apabila mereka merasa membutuhkan jaminan sosial. Hal tersebut sangat perlu diperhatikan mengingat betapa pentingnya jaminan sosial bagi freelancer di Indonesia pada era globalisasi.

Kemajuan teknologi digital dewasa ini mendorong warga Indonesia mulai beralih kepada pekerjaan di sektor informal (freelancer). Tenaga kerja freelancer pada umumnya bekerja di segala jenis pekerjaan dengan kenikmatan tidak perlu memikirkan pajak yang harus mereka bayar ke negara namun mereka tidak memiliki perlindungan dari negara dalam hal jaminan sosial. Padahal jaminan sosial merupakan skema yang telah legal/melembaga sebagai jaminan seluruh rakyat agar dapat memenuhi kebutuhan dasar hidup masyarakat yang layak (Undang-undang Nomor 11 Tahun 2009).

UUD 1945 pasal 27 ayat 2 menyatakan bahwa "Tiap-tiap warga negara berhak atas pekerjaan dan penghidupan yang layak bagi kemanusiaan". Selanjutnya UUD 1945 pasal 34 ayat 2 menyatakan bahwa "Negara mengembangkan sistem jaminan sosial bagi seluruh rakyat dan memberdayakan yang lemah dan tidak mampu sesuai dengan martabat kemanusiaan". Berdasarkan pemaparan UUD 1945 pasal 27 ayat 2 dan pasal 34 ayat 2 dapat disimpulkan bahwa UUD 1945 telah mengamanatkan jaminan sosial menjadi hak bagi setiap orang di Indonesia.

Undang-undang Nomor 11 Tahun 2009 pada pasal 9 ayat 2 menjelaskan bahwa jaminan sosial diberikan dalam bentuk asuransi kesejahteraan sosial dan bantuan langsung berkelanjutan agar rakyat dapat memenuhi kebutuhan dasar dan kelangsungan hidupnya secara layak. Selanjutnya hal yang sama juga disebutkan di dalam Undang-undang Nomor 32 Tahun 2004 yang menyatakan bahwa pemerintah daerah wajib untuk mengembangkan sistem jaminan sosial yang tertuang dalam pasal 22 huruf $\mathrm{H}$.

Sejatinya freelancer merupakan tenaga kerja lepas atau biasa disebut dengan istilah demand worker atau pekerja yang memiliki waktu flexible (bekerja ketika dibutuhkan saja). Walaupun demikian, freelancer di Indonesia tetap membutuhkan jaminan sosial dari pihak Pemerintah Indonesia. Freelancer termasuk ke dalam tenaga kerja yang bergerak di bidang informal, berdasarkan hal tersebut maka para freelancer perlu mendapatkan hak atas jaminan 
sosial tenaga kerja apabila kita mengacu UUD 1945 pasal 27 ayat 2 dan pasal 34 ayat 2 serta Undang-undang Nomor 11 Tahun 2009 pada pasal 9 ayat 2 dan Undang-undang Nomor 32 Tahun 2004 pasal 22 huruf H maka freelancer di Indonesia sebagai warga Indonesia juga berhak mendapatkan hak jaminan sosial layaknya seperti tenaga kerja formal.

Pertumbuhan freelancer di Indonesia sampai dengan saat ini terus mengalami pertumbuhan secara signifikan. Hal tersebut dikarenakan adanya perubahan persepsi masyarakat Indonesia terhadap profesi freelancer. Faktor lain yang menyebabkan profesi sebagai freelancer mulai dilirik oleh masyarakat Indonesia disebabkan oleh kehadiran marketplace yang membutuhkan tenaga mereka sehingga semakin menambah rasa percaya diri para freelancer tersebut sehingga seiring berjalannya waktu stereotype bahwa freelancer adalah pekerjaan yang tidak menjanjikan mulai hilang (Widodo, 2019). Faktor terpenting mengapa freelancer di Indonesia semakin berkembang disebabkan karena apresiasi positif yang diterima freelancer dari client-client mereka (individu maupun perusahaan) yang membutuhkan keahlian dan keterampilan khusus yang para freelancer miliki atau keterampilan yang tidak bisa dipenuhi oleh pegawai full time perusahaan (Anggrian \& Sumarlin, 2016; Mustofa, 2018).

Berangkat dari pemaparan di atas mengenai UUD 1945 dan Undang-undang yang menyatakan bahwa seluruh rakyat Indonesia wajib mendapatkan jaminan sosial serta ditambah lagi semakin berkembangnya tren orang yang memilih bekerja sebagai freelancer di Indonesia maka menurut hemat penulis perlu dipikirkan mengenai jaminan sosial yang diperuntukkan terhadap mereka yang memilih bekerja sebagai freelancer. Jaminan sosial yang dibutuhkan freelancer tersebut adalah jaminan sosial tenaga kerja. Jaminan sosial tenaga kerja merupakan sebuah perlindungan yang ditunjukkan bagi tenaga kerja dalam bentuk santunan, berupa uang sebagai pengganti dan pelayanan kesehatan. Jaminan sosial tenaga kerja sangat dibutuhkan bagi mereka yang termasuk dalam tenaga kerja di luar hubungan kerja (TKLH) karena status mereka sampai dengan saat ini belum memiliki jaminan sosial seperti yang dimiliki oleh para pekerja di sektor formal (Purnama, 2015). Mengingat berbagai macam risiko yang kemungkinan besar akan diterima oleh para freelancer, dewasa ini menurut hemat peneliti jaminan sosial ketenagakerjaan juga sangat dibutuhkan oleh para pekerja sektor informal (bukan hanya pekerja formal). 
Tantangan Kaum Freelancer Dan Pemerintah Indonesia Di Era Perkembangan Teknologi Digital (Analisis Kritik Globalisasi)

Urgensi jaminan sosial bagi para freelancer di Indonesia tentunya memiliki tantangannya tersendiri dalam proses pelaksanaannya. Berdasarkan hasil penelitian dari (Adillah \& Anik, 2015) menyatakan bahwa pelaksanaan program pemberian jaminan sosial bagi para freelancer di Indonesia sampai dengan saat ini masih mendapatkan hambatanhambatan. Hambatan tersebut seperti terbagi menjadi dua, yang pertama adalah hambatan dari pihak Pemerintahan Indonesia seperti masih lemah dan kurangnya kerjasama yang dilakukan Badan Penyelenggara Jaminan Sosial (BPJS) Ketenagakerjaan dengan para kaum tenaga kerja sektor informal (freelancer), masih kurangnya sosialisasi yang dilakukan Pemerintah Indonesia, sulitnya menghubungi dan menelusuri keberadaan tenaga kerja informal. Hambatan kedua yaitu hambatan yang bersumber dari sisi para tenaga kerja sektor informal sendiri yaitu pembayaran iuran dan jumlah pembayaran santunan yang bagi mereka tidak sesuai dengan tingkat kecelakaan kerja.

\section{Ancaman-Ancaman Lain Bagi Pekerja Freelancer di Indonesia}

Ancaman lain selain tidak adanya kepastian mengenai jaminan sosial dari Pemerintah Indonesia terhadap kaum freelancer adalah ketidakpastiaan mengenai jam kerja. Undangundang Nomor 13 tahun 2003 tentang Ketenagakerjaan menyatakan bahwa bagi karyawan yang bekerja 6 hari dalam seminggu, jam kerjanya adalah 7 jam dalam 1 hari dan 40 jam dalam 1 minggu. Sedangkan untuk karyawan dengan 5 hari kerja dalam seminggu, kewajiban bekerja mereka 8 jam dalam 1 hari dan 40 jam dalam 1 minggu. Undang-undang tersebut hanya berlaku bagi mereka yang bekerja di sektor formal, sedangkan mereka yang bekerja sebagai freelancer sampai dengan saat ini belum memiliki lindungan hukum mengenai jam kerja mereka. Sehingga sampai dengan saat ini banyak kasus yang didapatkan oleh freelancer mengenai jam kerja mereka yang tidak pasti ketika sedang berhadapan dengan client mereka.

Ancaman lain selanjutnya adalah nasib freelancer yang tidak memiliki gaji tetap di setiap bulannya maka mereka juga tidak akan pernah mendapatkan THR (Tunjangan Hari Raya) seperti mereka yang bekerja di sektor formal. Sehingga, konsekuensi mereka yang memilih bekerja sebagai freelancer tidak pernah mendapatkan THR, mereka harus bekerja semaksimal mungkin sebelum bulan Ramadhan dan Lebaran agar mendapatkan penghasilan yang banyak. Sehingga menjadi freelancer bukanlah menjadi perkara yang mudah selamanya apabila kita menganalisisnya berdasarkan jaminan-jaminan serta ancaman-ancaman yang mereka terima sebagai konsekuensi belum adanya lindungan hukum dari pemerintah. 


\section{Peran Pemerintah dan Kaum Freelancer dalam Menghadapi Fenomena Semakin Merebaknya Freelancer di Indonesia}

Upaya mengatasi permasalahan terbaru yang dihadapi masyarakat Indonesia dalam era globalisasi (teknologi digital) dewasa ini harus diselesaikan secara penuh oleh pihak Pemerintahan Indonesia. Peran dan tanggung jawab Pemerintah Indonesia mengenai permasalahan Jaminan Sosial yang belum tersedia bagi para freelancer di Indonesia sebenarnya sudah tertuang di dalam UUD 1945 yang menyatakan setiap tenaga kerja (warga negara Indonesia) berhak atas jaminan sosial tenaga kerja. Sama halnya dengan para pekerja di sektor formal, para freelancer juga memiliki potensi yang sama dalam hal risiko kerja. Freelancer juga memiliki hak yang sama seperti pekerja sektor formal dalam pemenuhan hak perlindungan jaminan sosial. Jaminan sosial tersebut dapat direalisasikan dalam bentuk asuransi kesehatan maupun jaminan pensiun juga. Para freelancer juga berhak dilindungi dari risiko kerja, seperti kematian, kecelakaan, sakit dan santunan dalam memasuki masa tua.

Penulis menyadari bahwa tawaran penulis tersebut bukanlah suatu hal yang mudah dilaksanakan Pemerintah Indonesia dalam proses pelaksanaannya. Perlu analisis kebijakan dan regulasi yang panjang dalam proses merealisasikannya, namun jika hal tersebut tidak direalisasikan oleh Pemerintah Indonesia dapat dipastikan akan muncul permasalahan baru bagi para kaum freelancer dan Pemerintahan Indonesia di kemudian hari. Di sisi lain, menurut hemat penulis cara kedua untuk mengatasi permasalahan ini juga dapat dilakukan dengan cara "from bottom to up". Maksudnya adalah mereka yang termasuk dalam aliansi freelancer Indonesia bisa menggunakan suara mereka sebagai rakyat Indonesia mengenai hak-hak yang seharusnya mereka juga dapatkan dari Pemerintah Indonesia. Sehingga dalam prosesnya dapat dengan mudah ditemukan titik temunya agar segala hak-hak para freelancer yang belum terpenuhi dewasa ini dapat direalisasikan oleh pihak Pemerintah Indonesia. 
Tantangan Kaum Freelancer Dan Pemerintah Indonesia Di Era Perkembangan Teknologi

Digital (Analisis Kritik Globalisasi)

\section{Kesimpulan}

Efek dari perkembangan teknologi digital pada era globalisasi ini telah memengaruhi stereotype masyakarakat Indonesia mengenai pekerjaan informal atau freelancer. Hal tersebut terbukti dengan semakin banyaknya komposisi freelancer di Indonesia. Hasil survei Badan Pusat Statistik (BPS) pada bulan Agustus 2018 menunjukkan ada sebanyak 56,8\% dan ada sekitar 4,55\% (sekitar 5,89 juta orang) yang bekerja sebagai freelancer.

Hal tersebut merupakan angin segar bagi Indonesia dikarenakan kondisi tersebut semakin memudahkan masyarakat untuk mencari kerja karena di Indonesia sendiri juga saat ini banyak yang membutuhkan tenaga darifreelancer baik individu maupun kantoran. Berdasarkan kondisi tersebut, ada beberapa hal yang menjadi ancaman bagi kaum freelancer di Indonesia. Salah satunya adalah mengenai jaminan sosial bagi mereka yang bekerja sebagai freelancer. Pemerintah Indonesia perlu memerhatikan hak para freelancer untuk mendapatkan jaminan sosial yang setara dengan apa yang didapatkan oleh para pekerja di sektor formal. Ancaman kedua yaitu mengenai ketidakpastian jam kerja bagi freelancer, dan ancaman ketiga bagi para freelancer Indonesia adalah pendapatan (gaji) mereka yang tidak menentu serta tidak pernah mendapatkan Tunjangan Hari Raya tidak seperti mereka yang bekerja di sektor formal. Para freelancer Indonesia juga berhak mendapatkan hak yang sama seperti para pekerja di sektor formal. Peran dan tanggung jawab Pemerintah Indonesia mengenai permasalahan Jaminan Sosial yang belum tersedia bagi para freelancer di Indonesia sebenarnya sudah tertuang di dalam UUD 1945 yang menyatakan setiap tenaga kerja (warga negara Indonesia) berhak atas jaminan sosial tenaga kerja. Oleh sebab itu, Pemerintah Indonesia maupun para kaum freelancer harus sama-sama berjuang menyelesaikan permasalahan tersebut karena baik pekerja di sektor formal maupun informal (freelancer) sama-sama memiliki potensi yang sama dalam hal risiko kerja. Apabila hak tersebut tidak dipenuhi maka akan berpotensi memunculkan permasalahan baru di kemudian hari bagi Pemerintah Indonesia dan kaum freelancer itu sendiri. Tawaran yang penulis ajukan dalam upaya mengatasi permasalahan tersebut adalah dapat dilakukan dengan cara membantu Pemerintah Indonesia agar sesegera mungkin mengatasi permasalahan tersebut dengan cara memberikan fasilitas yang berguna untuk mengatasi ancaman-ancaman yang diterima bagi pekerja freelancer di Indonesia. 


\section{Daftar Pustaka}

Adillah, S. U., \& Anik, S. (2015). Kebijakan Jaminan Sosial Tenaga Kerja Sektor Informal Berbasis Keadilan Sosial Untuk Meningkatkan Kesejahteraan. Yustisia Jurnal Hukum, 4(3), 558-580. https://doi.org/10.20961/yustisia.v93i0.3684

Anggrian, W. M., \& Sumarlin, A. W. (2016). Pengaruh Komitmen Tenaga Kerja Lepas terhadap Motivasinya dalam Perusahaan Keluarga di Sektor Informal. Jurnal Manajemen Teknologi, 15(2), 139-153. https://doi.org/10.12695/jmt.2016.15.2.3

Chandler, D., \& Fuchs, C. (2019). Digital Objects, Digital Subjects: Interdisciplinary Perspectives on Capitalism, Labour and Politics in the Age of Big Data. In European Journal of Communication (1st ed., Vol. 34, Issue 5). London. University of Wesminster Press. https://doi.org/https://doi.org/10.16997/book29

Grabher, G. (2001). Ecologies of Creativity: The village, the Group, and the Heterarchic Organisation of the British Advertising Industry. Environment and Planning A, 33(2), 351-374. https://doi.org/10.1068/a3314

Grabher, G. (2002). The Project Ecology of Advertising: Tasks, Talents and Teams. Regional Studies, 36(3), 245-262. https://doi.org/10.1080/00343400220122052

James, N., \& Busher, H. (2007). Ethical Sssues in Online Educational Research: Protecting Privacy, Establishing Authenticity in Email Interviewing. International Journal of Research and Method in Education, 30(1), 101-113. https://doi.org/10.1080/17437270701207868

Jati, W. R. (2013). Memahami Globalisasi sebagai Evolusi Kapitalisme. Global \& Strategis, $7(2)$ 241-258. https://ejournal.um.edu.my/index.php/ADAB/article/view/7789

Juliawan, B. H. (2018). Siapakah Manusia di Hadapan Revolusi Industri 4.0? Kecerdasan Buatan Dan Konsekuensinya Bagi Dunia Kerja Dan Pendidikan Tinggi. Yogyakarta. Sanata Dharma University Press.

Kharisma, G. (2019). Melihat Potensi Pertumbuhan dan Tantangan Pekerja Lepas Indonesia. TechinAsia. https://id.techinasia.com/pekerja-lepas-indonesia-2019

MUSTOFA. (2018). PEKERJA LEPAS (FREELANCER) DALAM DUNIA BISNIS MUSTOFA 1) Dosen STISIP Yuppentek Tangerang. Jurnal Muzaik, X(1), 19 25. https://media.neliti.com/media/publications/267958-pekerja-lepasfreelancer-dalam-dunia-bis-69ded095.pdf

Purnama, A. (2015). Analisis Perlindungan Jaminan Sosial bagi Pekerja Informal. Jurnal PKS, 14(2), 149-162. https:/www.google.com/url?sa=t\&rct=j\&q=\&esrc=s\&source=web\&cd=\&ved $=2$ ahUKEwivnuT67b3vAhWs7XMBHfCIA7kQFjAAegQIBRAD\&url=https $\% 3 \mathrm{~A} \% 2 \mathrm{~F} \% 2 \mathrm{Fejournal}$. kemsos.go.id\%2Findex.php\%2Fjpks $\% 2$ Farticle $\% 2 \mathrm{Fdo}$ wnload\%2F1317\%2F724\&usg=AOvVaw3TC7Cb-UP_zS8uonR2Mt1K

Shevchuk, A., Strebkov, D., \& Davis, S. N. (2019). The Autonomy Paradox: How Night Work Undermines Subjective Well-Being of Internet-Based Freelancers. ILR Review, 72(1), 75-100. https://doi.org/10.1177/0019793918767114

Tarigan, M. (2019). Anti Nganggur, Jadi Pekerja Lepas ala Big Agent Bisa Jadi Pilihan. Tempo.Co. 
Tantangan Kaum Freelancer Dan Pemerintah Indonesia Di Era Perkembangan Teknologi Digital (Analisis Kritik Globalisasi)

Watson, A., \& Beaverstock, J. V. (2016). Transnational Freelancing: Ephemeral Creative Projects and Mobility in the Music Recording Industry. Environment and Planning A, 48(7), 1428-1446. https://doi.org/10.1177/0308518X16641412

Widodo, A. S. (2019). Peran Internet dalam Meningkatkan Jumlah Pekerja Lepas di Indonesia. NYIMAK: Journal of Communication, 3(2), 191-202. http://jurnal.umt.ac.id/index.php/nyimak 